\section{VicHealth}

VicHealth Leading Thinkers:

Behavioural Insights \& Gender Equality
For policymakers, health promotion practitioners, researchers, journalists, writers and sports organisations.

May 2020

\title{
Buried treasures and missed opportunities in Victorian sports reporting
}

Big data analysis of gender portrayal in print media in Victoria, Australia from 2014 to 2019 


\section{VicHealth Leading Thinkers Behavioural Insights and Gender Equality Initiative 2016-2021}

This research forms part of the VicHealth Leading Thinkers Initiative, which is designed to connect international thought leaders with policymakers and key local experts.

Its aim is to generate new thinking, inspire momentum, enable change, support deepening relationships across sectors and deliver positive health and wellbeing for all Victorians.
Pioneering global approaches in behavioural insights are being translated into practical strategies and applications for Victorian and Australian organisations seeking to transform the underlying drivers of gender equality (unconscious bias, gender stereotypes, gender role models and social norms).

We would like to acknowledge and thank VicHealth Leading Thinkers Dr Jeni Klugman and Professor Iris Bohnet for this groundbreaking study.

\section{Professor Iris Bohnet}

Iris Bohnet is the Albert Pratt Professor of Business and Government and the Academic Dean of Harvard Kennedy School. She is a behavioural economist, combining insights from economics and psychology to improve decisionmaking in organisations and society, often with a gender or cross-cultural perspective. Her most recent research examines behavioural design to de-bias how we live, learn and work.

She is the author of an award-winning book about gender equality and advises governments and companies on the topic around the world. Professor Bohnet is the co-director of Harvard's Women and Public Policy Program, and the faculty chair of the executive program: "Global Leadership and Public Policy for the 21st Century" for the World Economic Forum's Young Global Leaders.

She serves on the boards, advisory boards or as a patron of Credit Suisse Group, Applied, Edge, genEquality, TaketheLeadWomen, We Shape Tech, Women in Banking and Finance, and the UK Government's Equalities Office as well as numerous academic journals. She was named one of the Most Influential People in Gender Policy by Apolitical in 2018 and 2019 and received an honorary degree from the University of Lucerne, Switzerland, in 2016.

\section{Dr Jeni Klugman}

Jeni Klugman is Managing Director at the Georgetown Institute for Women, Peace and Security. Dr Klugman's previous positions include Director of Gender and Development at the World Bank, fellow at the Kennedy School of Government's Women in Public Policy Program at Harvard University, and director and lead author of three global Human Development Reports published by the UNDP.

She is a member on the Lancet Commission on Gender and Global Health, and regularly participates in major global gender policy initiatives. Most recently these include: the Lancet Series on Gender Equality, Stanford University; the Bill and Melinda Gates Foundation on Women's Economic Empowerment; and the Council on Foreign Relations' Advisory Committee on Economic Inclusion and Global Growth. She is currently advising UN Women, the World Bank and partners on justice for women; the World Bank on gender dimensions of forced displacement; and the UN Development Program on human mobility.

Jeni holds a PhD in Economics from the Australian National University and postgraduate degrees in both Law and Development Economics from the University of Oxford where she was a Rhodes Scholar. She was included in the Apolitical Inaugural List of the World's 100 Most Influential People in Gender Policy in 2018 and in 2019.

\section{Acknowledgements:}

VicHealth would also like to acknowledge the following people who assisted in the preparation of this report:

Suzanne Schwarz, Olja Busbaher and Sandie Szawlowski were integral members of the team, which developed the methodology and analysis. Jeff Borland and Nick Richardson provided valuable early feedback. Alex Codoreanu, Arezou Soltani Panah and Lewis Gurr-Stephen significantly updated and extended the analysis.

This study is based on Dow Jones content available via the Data News and Analytics (DNA) platform found at: www.dowjones.com/news-you-can-use/ 


\section{Leading Thinker foreword}

\author{
As highlighted in a recent report of the United \\ Nations Secretary General, the media plays \\ a critical role in perpetuating and countering \\ discriminatory norms and gender stereotypes ${ }^{1}$. \\ When Professor Iris Bohnet and I began working \\ with VicHealth to help bring behavioural insights \\ into efforts to promote gender equality, it \\ was clear from the outset that sport plays an \\ important role in Australian society and media.
}

We wanted to focus on social norms, because these reflect shared expectations and informal rules about how people should behave. As I investigated with co-authors in a recent special issue of The Lancet ${ }^{2}$, ignoring gender norms and inequalities undermines the health of everyone - women and girls; boys and men; and gender minorities.

Social norms shape opportunities for women and girls in a range of settings. Importantly, such norms can also limit choices, even in settings like Victoria, where explicit barriers to equality have been removed and government is committed to a vision in which all Victorians are visible and represented, not only at work, but also in communities, sport and media.

The last five years have been a time of change in Victoria, with women making high profile inroads into traditionally male domains, such as Australian Rules Football and even the Melbourne Cup. And with major media corporations stating commitment to more equitable coverage.

How was this being reflected in the newspaper text coverage of sports in Victoria during this time?

As part of our contribution to a more systematic understanding of gender bias in Victoria, we used a big data analysis, made possible by improvements in data availability and computational techniques.
The volume of the analysis is significantly more than previous reviews that were conducted manually. The goal was to systematically document the extent and nature of bias in sports reporting, to inform more conscious management and staff decisions about gender balance in coverage.

Working together with colleagues from Swinburne University, we processed five years of data to analyse 241,781 written articles and 123 million words. There were some important findings - some of which are encouraging, others much less so. The highlights are presented here, with a fuller version being published separately with technical details.

(f)

\section{We wanted to focus on social norms, because these reflect shared expectations and informal rules about how people should behave."}

We hope that the findings will make a constructive contribution to conversations about what needs to be done to tackle gender inequality in ways that will generate gains for all Victorians.

\section{Dr Jeni Klugman}

Managing Director

Institute for Women, Peace and Security

Georgetown University 


\section{VicHealth foreword}

The notion that Victorians are happy with the coverage of female sports in the media is not supported by research. We know that more than half of women and 37 per cent of men are dissatisfied with the current level of media coverage of women's sport and want more ${ }^{3}$.

Australia's female tennis players, swimmers, surfers and golfers, and the national women's cricket, soccer and netball teams have recently all achieved incredible international success. But, are Australians being given sufficient opportunities to read about, celebrate and be inspired by these successes? Is there a discrepancy between the amount and nature of media Australians consume about male athletes and female athletes?

We welcomed the opportunity to apply machine learning techniques to allow a truly comprehensive and complete review of the last five years of print-based sports reporting in Victoria so we could answer these questions definitively.

This study is important for anyone who talks about, writes about or reports on sport. It is for media, sporting organisations and codes, experts, athletes and community members. It is also for researchers who can deepen the analysis further to include elements such as the use of images or placement in the newspaper, or to investigate the norms in broadcast or online articles.

At a time when half of Australian women are not exercising enough and worry about being judged while exercising (see thisgirlcan.com.au), seeing successful female athletes in the media could light the way for women and girls to follow - after all, you can't be what you can't see.
The good news in this study is encouraging, and fortunately some excellent materials already exist as references for writers:

1. Change Our Game, a suite of initiatives delivered by the Office for Women in Sport and Recreation in the Victorian Government, includes a range of guidelines to support community sport and recreation organisations looking to develop inclusive marketing and communication practices. Two key resources include guidelines for marketing and communications. The first details strategies for marketing to women, selecting imagery, using social media, using inclusive language and terminology. The second provides recruitment and retention guidelines, to encourage sport and active recreation organisations to utilise inclusive practices to attract and retain more women in their workforce and in positions of leadership: changeourgame.vic.gov.au

2. International Olympic Committee guidelines for gender balanced representation: stillmed.olympic.org

A future where we see a level playing field in how we celebrate the success of our male and female athletes need not be too far away.

\section{Nithya Solomon}

Executive Lead Innovation Office

VicHealth

\section{This study is important for anyone who talks about, writes about or reports on sport."}




\section{Research in context}

\section{Key findings of this study}

1. Content analysis revealed comparable and unbiased portrayal of men and women in sports reporting. For example, references to appearance, the use of gendered language and other measurable gender biases are infrequent in sports articles about both men and women.

2. Opportunities to read articles about women in sport are scarce and do not match the levels of female participation in sports, or the demand for articles about female sports. The vast majority of newspaper sports articles centre on men.

3. Female journalists are more likely to write about women in sport, but only account for 12 per cent of sports articles. The share of women writing sports articles fell from 18 per cent to 12 per cent over the five-year study period.

Sport is important, if not central, to the Victorian community. Millions of women and men, girls and boys participate in sport on a regular basis, and millions more are avid spectators and consumers of news about sports.

Media reporting plays a key role in shaping perceptions about sport and influencing social and gender norms. Sports media also shapes popular views about role models and success in sport. In fact, the centrality of sport and sports media is well recognised by the Victorian Government, as reflected in the gender strategy (see Figure 1). Research conducted for VicHealth has also found substantial levels of unmet demand for media coverage of female sports (see Figure 2).

\section{Figure 1: Sports media and the Victorian Gender Equality Strategy 2016}

The vision of the Victorian Gender Equality Strategy is that all Victorians are visible, have an equal voice and occupy decision-making roles not only at work, but in communities, sport, media and the arts.

The indicators to measure progress include:

- reduced reports of everyday stereotypes and sexism

- increased recognition of women's expertise (media, sports, the arts)

- increased representation of women in media, professional sports and at all levels of leadership.

Source: Women Victoria, www.vic.gov.au/our-gender-equality-strategy
To date, most research on gender portrayal in sports reporting has relied on the manual review of news reports, which is both time-consuming and resource-intensive, entailing a trade-off between volume and depth of the analysis.

This study is the first ever, large-scale analysis of the extent and nature of the portrayal of women and men in Victorian sports print media. It provides important evidence to both inform the debate and to highlight challenges and opportunities.

\section{Evidence before this study}

- A study of five major British news outlets found that female athletes featured in less than 4 per cent of sports-related news, mainly in feminine-type sports like tennis or horse riding ${ }^{4}$. Similarly, in New Zealand, sportswomen only appeared in about 6 per cent of news reports 5 .

- Where women were reported on in sports, studies found an emphasis on appearance and sexist language, such as reporting on weight loss or the colour of nail polish of female tennis players ${ }^{6}$.

- In the US, male journalists in print media continue to outnumber female reporters by roughly two to one $\mathrm{p}^{7}$, a ratio that was found to parallel Australia and New Zealand ${ }^{8}$.

- The 2019 Women for Media Report: 'You can’t be what you can't see'9 took a snapshot of Australia's most influential news sites on four consecutive Thursdays in October 2018 and found that, by and large, women are not quoted as the experts nor the sources - and that for sports stories in particular, men constituted 95 per cent of direct sources.

- Recent analysis of three decades of sports reporting in The New York Times found that just 5.2 per cent focus on women's sports and female athletes ${ }^{10}$.

Only one fifth of women and one third of men in Victoria feel there is enough media coverage of women in sports.

Figure 2: Response to: "There is enough on-field/on-court TV, radio and newspaper coverage of female sports"

\begin{tabular}{|c|c|c|c|}
\hline & \\
\hline & Total & Men & Women \\
\hline Disagree & $44.2 \%$ & $36.6 \%$ & $51.7 \%$ \\
\hline Neither agree or disagree & $28.8 \%$ & $29.6 \%$ & $27.9 \%$ \\
\hline Agree & $26.9 \%$ & $33.8 \%$ & $20.4 \%$ \\
\hline
\end{tabular}




\section{Over $\mathbf{2 4 0 , 0 0 0}$ articles and $\mathbf{1 2 3}$ million words analysed: methodology highlights}

\author{
In this big data analysis, we utilised supervised \\ machine learning, a computational method that \\ enables analysis on a large scale. This study \\ examined print media sources, focusing on \\ newspapers but not magazines, periodicals, \\ graphics or other types of print media.
}

This data was analysed using Swinburne's OzSTAR supercomputer, one of the most powerful in Australia with a performance peak of 1.2 petaflops. A petaflop is a unit of computing speed equal to one thousand million million $\left(10^{15}\right)$ floating point operations per second (Collins Dictionary online, 2020, petaflop entry).

For Victoria this amounted to 241,781 articles and represented 123 million words.

We developed a coding instrument to systematically measure the quantitative representation of women both in the sports news and general news, and the extent to which sport-related news stories contain language or content reflective of gender bias.

Of the 241,781 articles, the number of articles where a person was identified as the main 'named entity' was 74,826 , representing 37.7 million words. This is the volume of data on which the coding instrument could be applied to generate the data and insights presented in the following pages.
Content reflective of gender bias could include:

- use of gendered language - the table below illustrates the types of gendered language we found in the content analysis (e.g. describing women athletes as fragile or emotional)

- mention of gendered roles (e.g. wife, father, sister, son)

- references to relationship or family status (e.g. athlete has two children, athlete is engaged to be married)

- mention of physical attributes or appearance (e.g. make-up, outfit, hair of athlete/team; body shape, weight, strength of athlete; race or ethnicity)

- diminishing successes (e.g. attributing achievements to others, such as having a supportive coach or supportive family).

Note that the data did not allow analysis of other elements of sports reporting, such as the use of images or position in paper (e.g. back page or proximity to back page). These elements may also impact on understanding gender bias.

Further details about the method will be available in a technical paper - to be published.

See Glossary for definitions of key terms.

\section{Figure 3: Examples of gendered language in the sample}

\begin{tabular}{|l|l|}
\hline Classifications & Examples found in sample \\
\hline Feminine traits & $\begin{array}{l}\text { emotional, coy, feisty, finesse, flamboyant, fragile, wild child, vulnerable, sweet-natured, nice, } \\
\text { young (as in childlike), tenderness, understanding, affectionate, elegant, femininity }\end{array}$ \\
\hline Masculine traits & $\begin{array}{l}\text { aggressive, ruthless, brutal, ferocious, iron-willed, brave, competitive, courageous, daring, gutsy, } \\
\text { intelligent, powerful, smart, top dog, outspoken, strong-willed }\end{array}$ \\
\hline $\begin{array}{l}\text { Depicts team } \\
\text { achievements/defeat } \\
\text { in masculinised terms }\end{array}$ & $\begin{array}{l}\text { ambushed, assault, deadly, killed, terrorizing, demolition, brutal smashing, wreaking havoc, } \\
\text { domination, outmuscled, workhorse, warrior, killer blow, beast mentality, caged lions, crushing, } \\
\text { destructive, devastating, fierce warrior, foot soldier, spearheaded smash, tormenting, weaponry, } \\
\text { tower of strength, tore to shreds, menace, bulldozed, gorilla, hammering, giantkiller }\end{array}$ \\
\hline
\end{tabular}




\section{Great news: content analysis showed unbiased portrayal of men and women in sports reporting}

Our detailed analysis of language in sports articles generally found no significant differences in the ways that males and females were portrayed in sports articles, in terms of the use of gendered language and attribution of success. And references to their physical attributes were relatively infrequent overall.
These findings stand in welcome contrast to earlier studies on smaller samples.

The snapshot for the July-July 2018/19 year is below (Figure 4), which was also representative of the entire period of the analysis.

One exception was that sports articles about women were more likely to mention their gender roles, although this was still only in a minority (8 per cent) of articles (see Figure 5).

Figure 4: Percentage of articles with gendered content for males and females reported in Victorian sports print media articles, 1 July 2018 - 30 June 2019

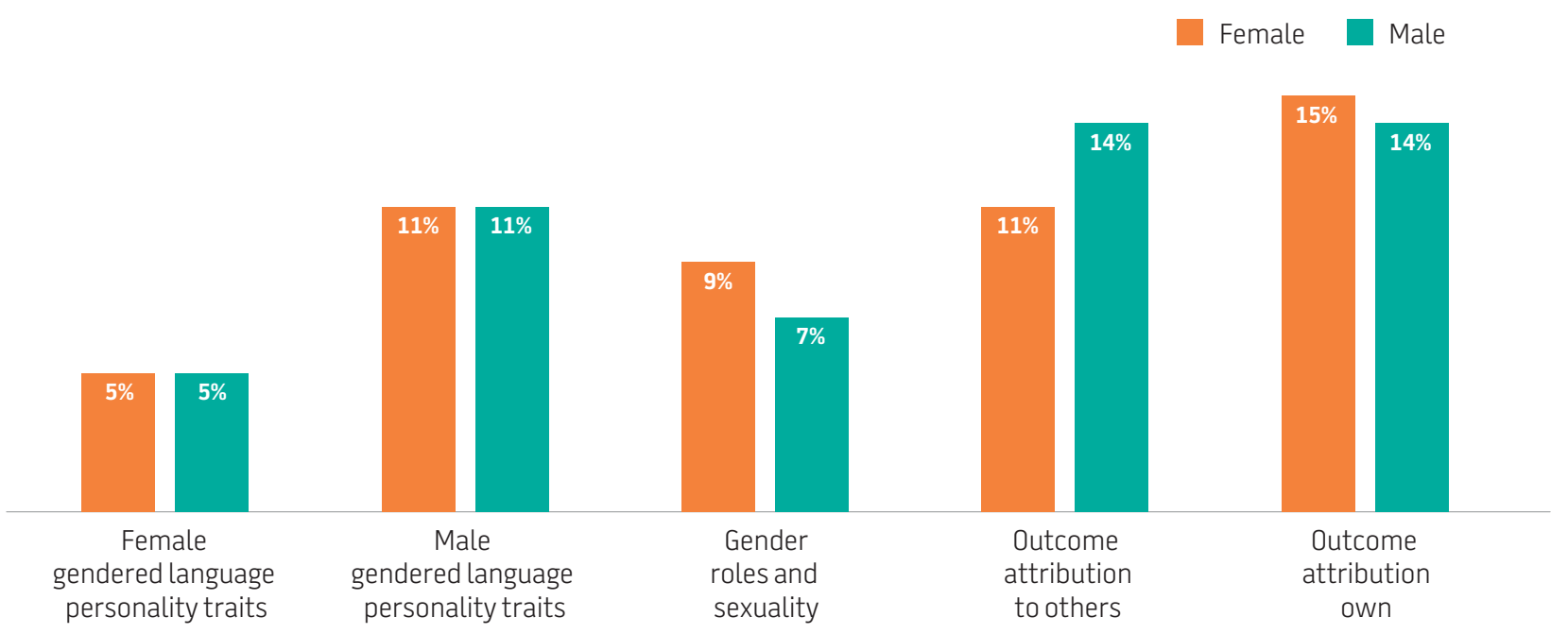

Figure 5: Reporting on gender roles in Victorian print media by gender of sportsperson

Female 2014/15 - 2018/19

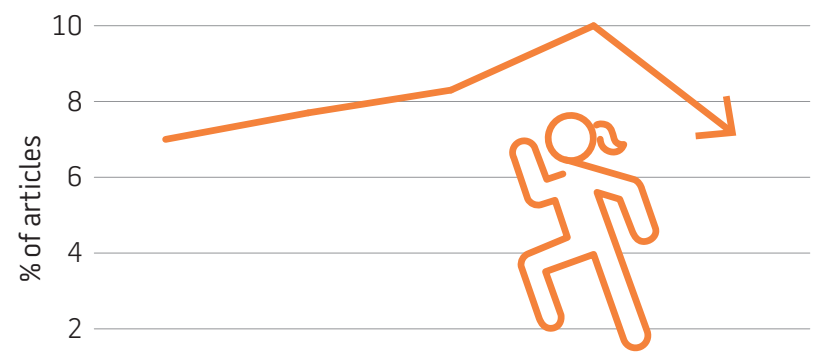

0
Male 2014/15 - 2018/19

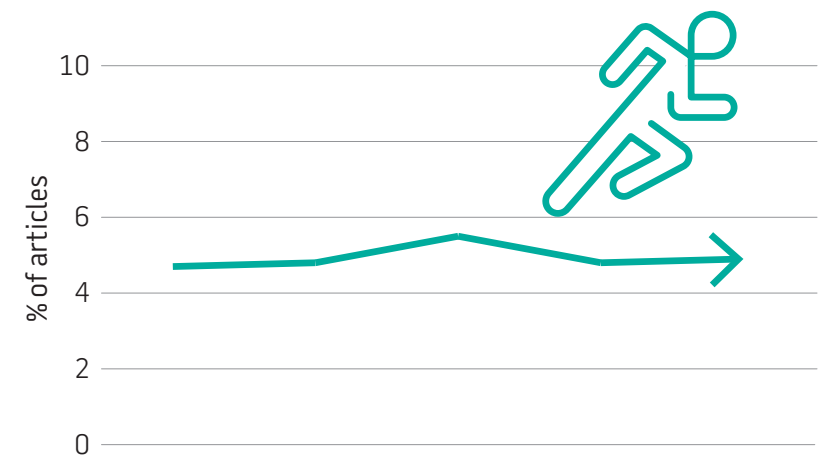




\section{However, opportunities to read about women in sports reports were scarce}

There was significant under-reporting of females in sport over the five-year period in newspaper articles, despite temporary boosts around major events (Figure 6).
The net result is that, over the five years, 30.2 million words were written in articles about men, compared to 3.3 million about women (Figure 7).
30.2 million words written in articles about men

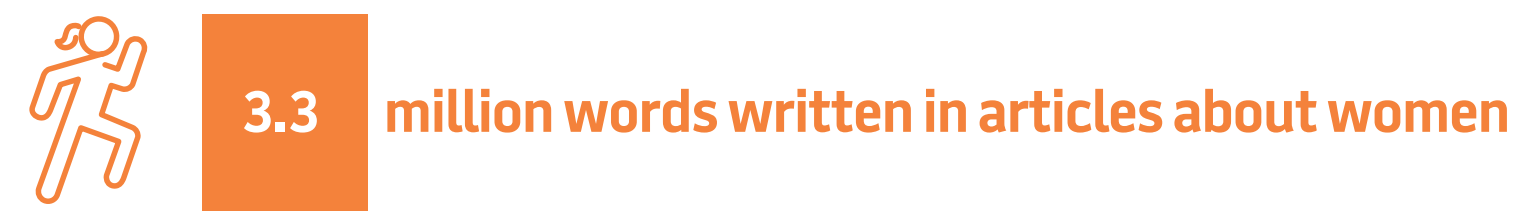

Figure 7: Total words written about females and males in Victorian sports articles in major news outlets 2014-2019

\section{Figure 6: All sports reporting of male and female sportspeople in Victorian print media 2014-2019}

\section{0}

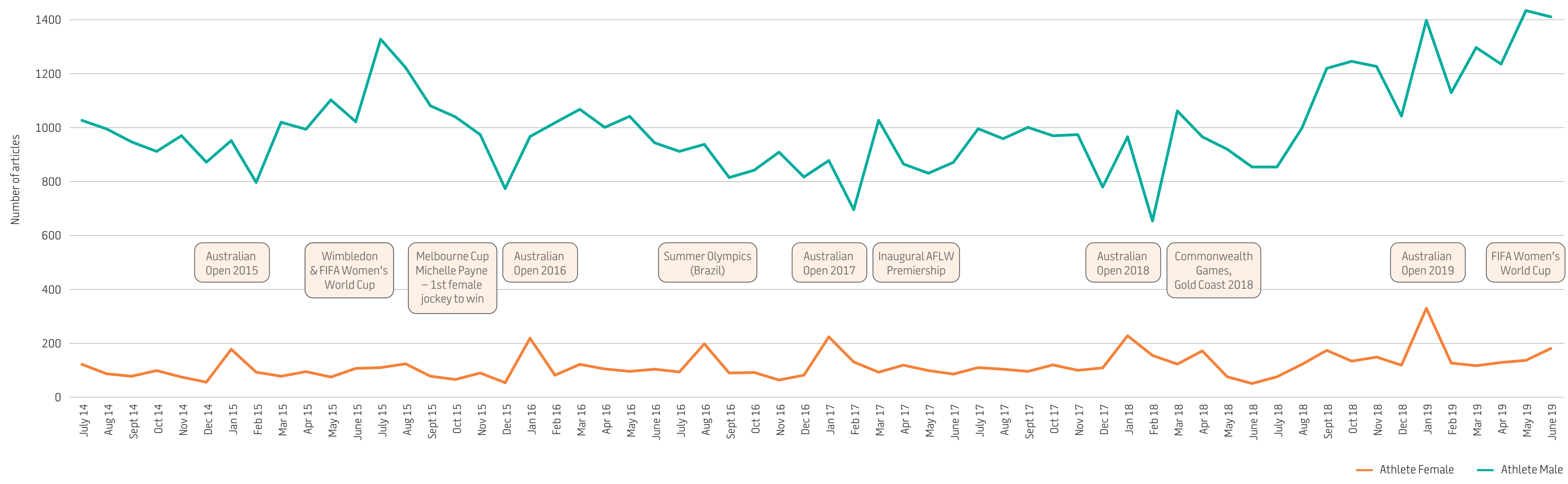

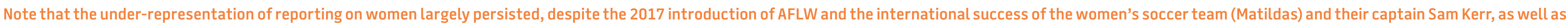
the world number one rankings of Australian women in tennis (Ashleigh Barty), surfing (Sally Fitzgibbons) and golf (Hannah Green) in 2019. 
The five-year trend is shown for three major sports below - the share of women being reported in AFL and cricket is virtually flat over the period. Tennis shows boosts to reporting about women at different times (typically around the Australian Open and French Open) but these were not sustained over time (refer Figures 8-10).

\section{Figure 8: AFL reporting 2014-2019}
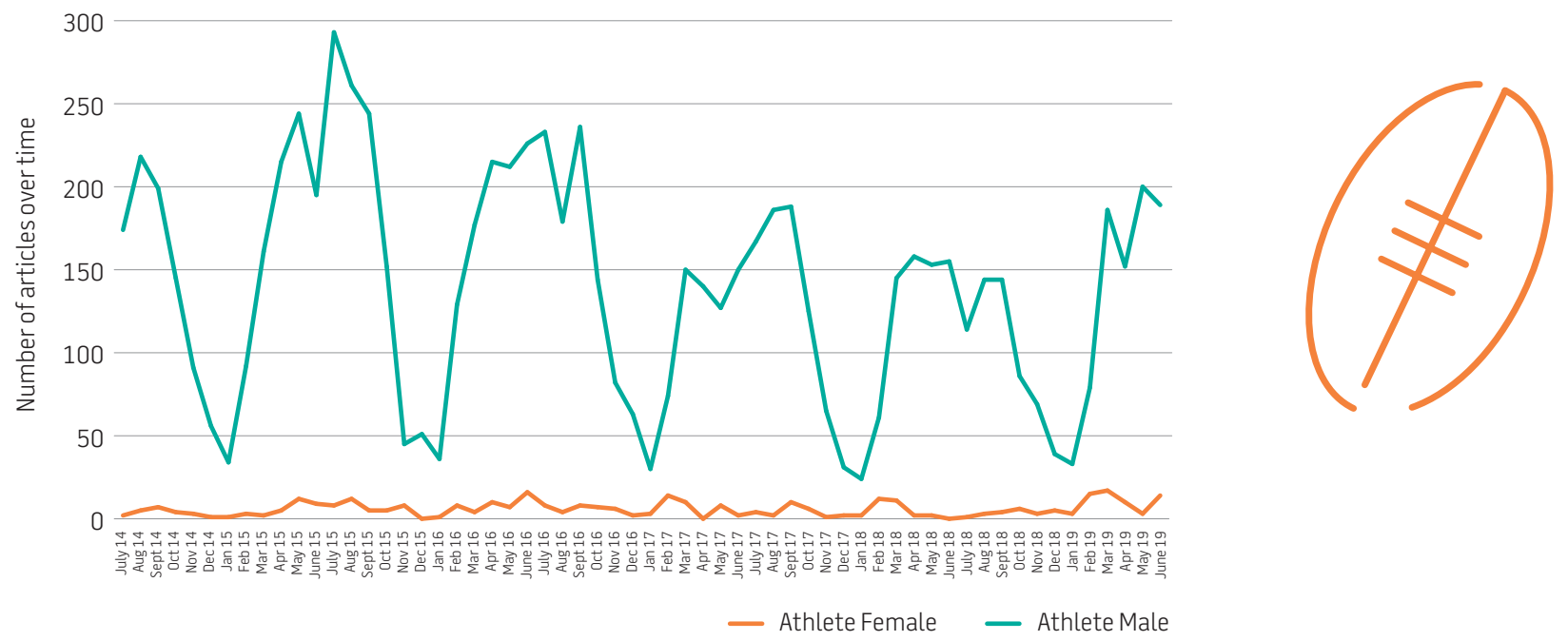

Figure 9: Cricket reporting 2014-2019
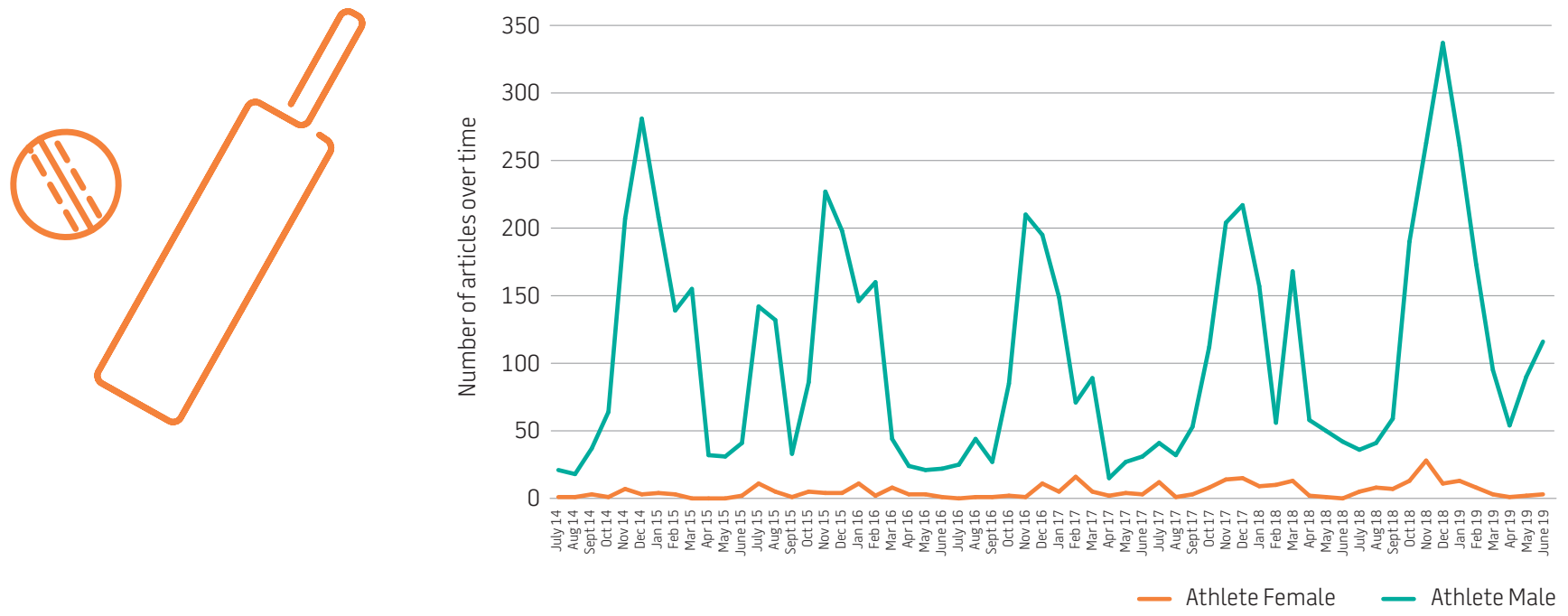

Figure 10: Tennis reporting 2014-2019



\section{Three opportunities to address unmet demand for articles about women in sport}

\section{(1) Bridge the gap between participation levels and current share of media coverage in these sports.}

The share of media about women in sport is in general less than the share of women playing the sport - as shown for the past year in Victoria in Figure 11 below.

This shows the trend in under-representation of women in media coverage and over-representation of men in media coverage. For example, tennis has 48 per cent female participation, but women featured in only 28 per cent of the media coverage. In contrast, men featured in 72 per cent of the media coverage despite representing 52 per cent of participation.

Figure 11: Proportion of articles about females and males for individual sports compared to participation rates 2018-19

Female Male

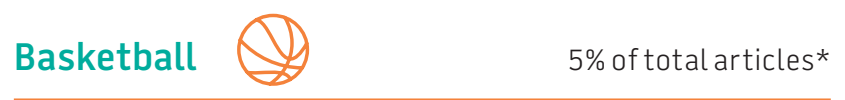

\section{Share of participation**}

$$
32 \%
$$

$68 \%$

Share of

reporting

$$
18 \%
$$

$82 \%$

Football



$15 \%$ of total articles*

Share of
participation**

\section{$16 \%$}

$84 \%$

Share of reporting

$5 \%$

$95 \%$

$<1 \%$ of total articles*

Hockey<smiles>C1CC2(C1)CC2</smiles>

Share of participation**

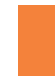

$$
41 \%
$$

$59 \%$

Share of

reporting

\begin{tabular}{l|l}
$32 \%$ & $68 \%$ \\
\hline
\end{tabular}

$10 \%$ of total articles*

Tennis
$\begin{aligned} & \text { Share of } \\ & \text { participation** }\end{aligned}$
$\begin{aligned} & \text { Share of } \\ & \text { reporting }\end{aligned}$
$\begin{aligned} & \text { 48\% of total articles* } \\ & \text { 28\% }\end{aligned}$

Cricket

\begin{tabular}{|c|c|c|}
\hline $\begin{array}{l}\text { Share of } \\
\text { participation** }\end{array}$ & $14 \%$ & $86 \%$ \\
\hline $\begin{array}{l}\text { Share of } \\
\text { reporting }\end{array}$ & $6 \%$ & $94 \%$ \\
\hline
\end{tabular}

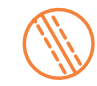

$17 \%$ of total articles*

Golf

$3 \%$ of total articles*

Share of participation**

\begin{tabular}{|c|c|}
\hline hare of & $6 \%$ \\
\hline
\end{tabular}

\section{$27 \%$}

$73 \%$

Soccer

$9 \%$ of total articles*

Share of participation**

$20 \%$

$80 \%$

Share of reporting

$5 \%$

$95 \%$

\begin{tabular}{lcc} 
Track (Athletics) & 1\% of total articles* \\
\hline $\begin{array}{l}\text { Share of } \\
\text { participation** }\end{array}$ & $44 \%$ & $56 \%$ \\
$\begin{array}{l}\text { Share of } \\
\text { reporting }\end{array}$ & $29 \%$ & $\mathbf{7 1 \%}$
\end{tabular}

* Refers to total articles in the study sample. See methodology in Section 2 for description of the study sample.

** Refers to percentage share of people playing the sport and is taken from the AusPlay 2018-19 survey (see note below) and includes organised and unorganised participation over the past 12 months. Organised sport refers to sport played through an organisation, like a club or a gym; or at a venue, like a pool or an oval. It typically includes all membership of sporting clubs.

Note: Share of female population in Victoria participating in any sport or physical activity in 2018-19 is $86 \%$. Participation data is from the AusPlay $2018-19$ survey and shows adult women (15 years and over) as a percentage of total people participating over the past 12 months in the sport. This includes participation activities for sport, for exercise or for recreation. For further information see www.clearinghouseforsport.gov.au/research/smi/ausplay/ results/state 
(2) Increase coverage of sports with high female participation, given that male sports currently dominate sports media coverage.

The sports that receive the greatest share of coverage in the media are those where participation is predominantly male. This is represented in Figure 12. Also see Figure 11 for sports with high female representation.
Figure 12: Share of sports articles written about individual sports in Victorian print media 2014-2019

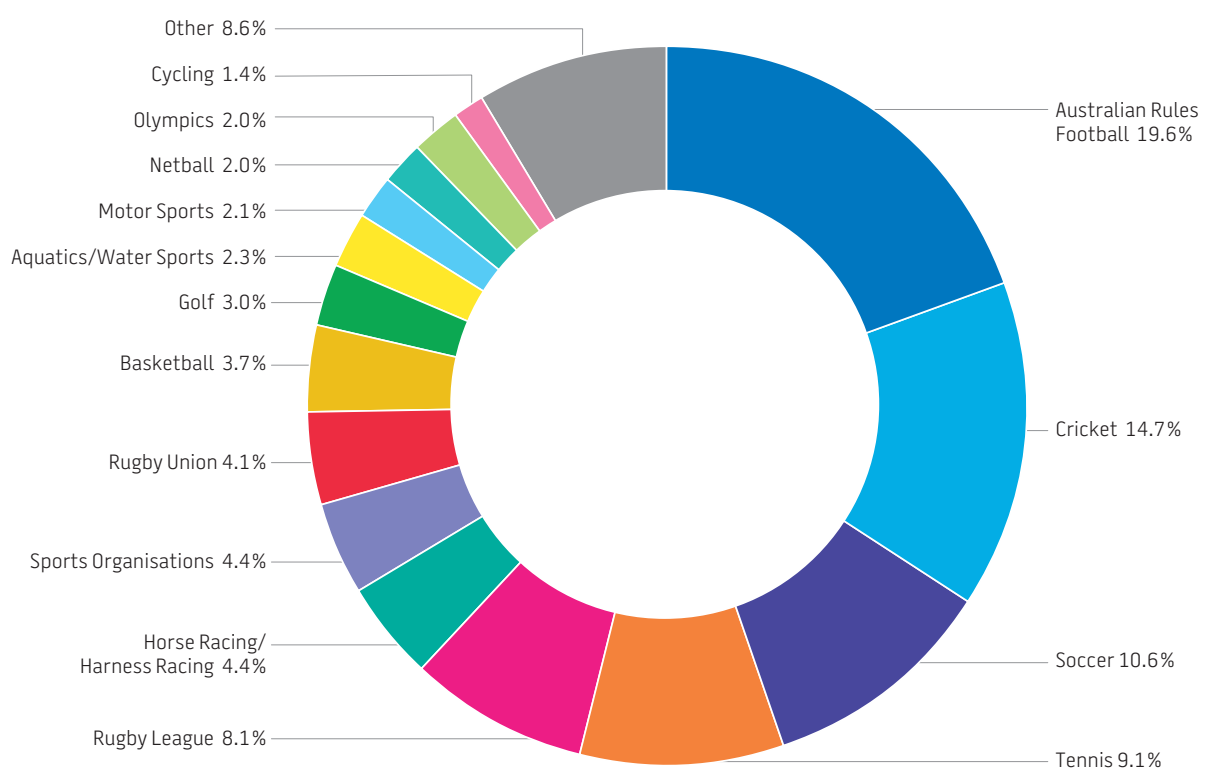

\section{(3) Encourage female journalists because they are more likely to write about women's sport.}

Female journalists authored only about one in eight of all sports media articles in our sample, but they are more likely than male journalists to write about women.

We can see that female journalists are more than three times more likely to write sports articles about female athletes. Indeed, the data suggests that if there were only male journalists, the average representation of women in sports articles would drop to about 6 per cent.

This suggests that increasing female inclusion in sports media would be a good way to boost the coverage of women in sports - yet over the fiveyear period we analysed, the share of women writing sports articles fell by one third over the period, from 18 to 12 per cent.
Figure 13: Share of articles about female and male sportspeople written by female and male journalists 2014-2019

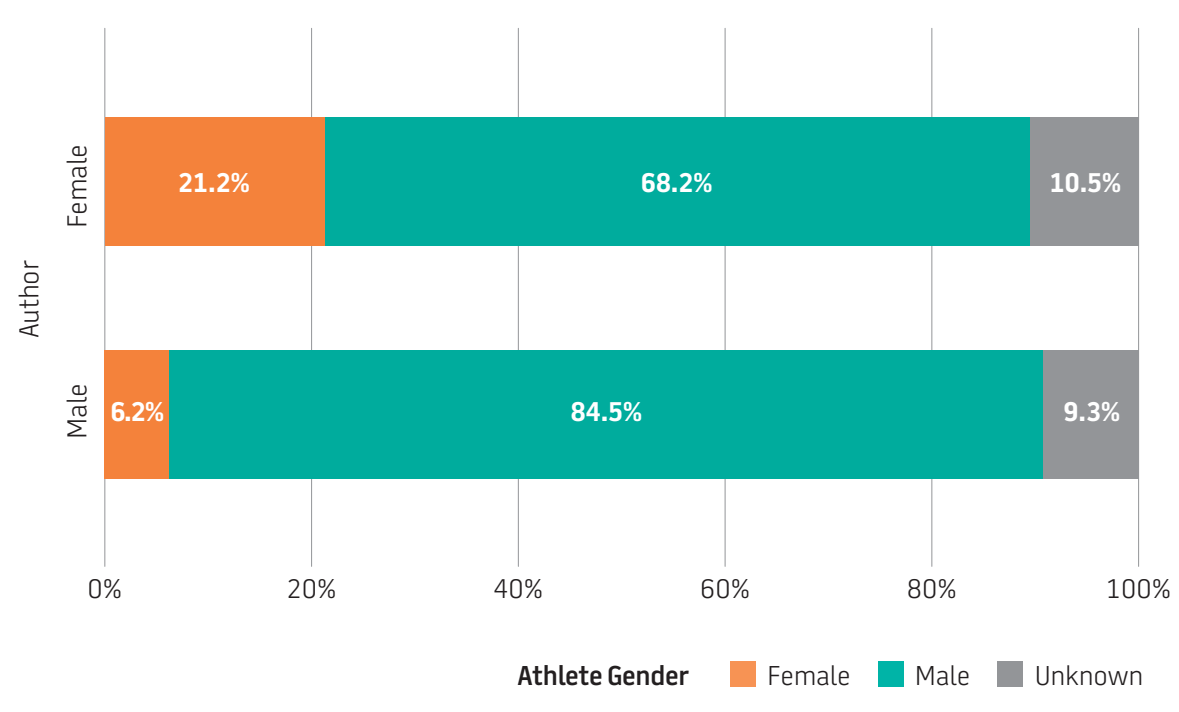




\section{Conclusions and implications}

This research reports on the first ever large-scale analysis of the extent and nature of the portrayal of women's and men's sport in newspapers in Victoria. It is especially timely with the rise of women's leagues in several elite sports, and the Victorian Government's focus on increasing the representation of women in sports.

The representation of women in media and sports is also firmly on the global agenda, as reflected in recent reports of the United Nations Secretary General on the 25th anniversary of the Beijing Platform for Action.

Our big data analysis covered the Victorian sports print media universe of the period, specifically some 241,781 articles and 123 million words. At the same time, we recognise that gender portrayals in sports print media are shaped by contextual and other factors that could not be addressed as part of this analysis - for example the imagery used and page placement.

The great news is that Victorian sports journalists are portraying men and women in a comparable way in print media, with no bias in the way men and women are reported. When women are reported, their successes are not diminished and there is no evidence of disproportionate attention to women's physical appearance or personal relationships.

However, opportunities to read about women in sports remain scarce. Our analysis reveals massive under-representation of women in sports media in Victoria. The gap exceeds 8:1, and has not changed much over time, even with major events like the introduction of a women's Australian Football League and Australian women topping world rankings in cricket, tennis, soccer, surfing and golf.

Not only is the lack of recognition of women unrepresentative, it may also discourage girls and women from participating in sport. Women are as physically active as men, but far less likely to participate in organised sports ${ }^{11}$ - possibly because women in sports are so absent from media portrayals and because role models are not reported. While all physical activity is good, participation in organised sport brings further benefits to mental health, social connection and wellbeing ${ }^{12}$.

\section{Our empirical findings are a major step forward in a better understanding of gender portrayal in sports reporting and what needs to be done to reach gender equality goals in women's sports reporting."}

Our findings may also be associated with the scarcity of women in sports journalism. Women journalists account for only 12 per cent of all sports articles published in 2018-19, but they wrote more than 30 per cent of sports articles about women. It appears that women journalists are crucial to expanding the media coverage of women's sport, yet the share of women writing articles has fallen - from 18 to 12 per cent since 2014.

We also found encouraging evidence in the popular appetite for greater coverage of women in sports - especially, but not only, from women themselves.

Our empirical findings are a major step forward in a better understanding of gender portrayal in sports reporting and what needs to be done to reach gender equality goals in women's sports reporting.

The evidence demonstrates that significantly more reporting on women in sports would give Victorian women and girls the chance to see the same opportunities and role models for themselves in sports as Victorian men and boys do. 


\section{Big data analysis}

Big data analysis involves using computational tools and techniques to discover patterns and other useful information in datasets that are too large for traditional data processing software. Machine learning and natural language processing are two tools used in this study to analyse the text.

\section{Content analysis}

Content analysis is a text analysis process that involves defining categories, sorting text into categories and analysing the relationships among the categories. It can be qualitative (focused on meanings), quantitative (counting the frequencies or other characteristics of categories), or a combination of both.

\section{Gender equality}

The World Health Organization (WHO) defines gender equality as "the absence of discrimination on the basis of a person's sex in opportunities, the allocation of resources and benefits, or access to services" ${ }^{\prime 13}$.

\section{Gendered social norms}

Social norms are the informal rules that govern the behaviour of individuals in groups, communities, cultures and societies. They are the behaviours that are socially acceptable and expected in that environment ${ }^{14}$.

\section{Gender stereotypes}

Gender stereotypes are culturally defined expectations about the sexes.

\section{Gendered language}

Words, expressions or phrases that suggest masculinity or femininity. For example, 'gutsy' may be more associated with masculinity whereas 'coquettish' may be thought of as more of a feminine word or action.

\section{Named entity}

Named entity is the term used in natural language processing (see Big Data above) that refers to identifiable names of real-world people, teams or organisations found in text.

\section{Sports participation}

Sports participation can refer to regular or infrequent, formal or casual participation. Regular participation can be measured by club membership or participation in regular competitions. 
1 Report of the Secretary-General, Review and appraisal of the implementation of the Beijing Declaration and Platform for Action and the outcomes of the twenty-third special session of the General Assembly, Economic and Social Council, E/CN.6/2020/3

2 Gupta, G R, Oomman N, Grown C, et al. (2019) Gender equality and gender norms: framing the opportunities for health, The Lancet

3 VicHealth (2017) Gender Equality in Sports Survey 2016: VicHealth internal analysis, Unpublished report

4 Godoy-Pressland A (2014), 'Nothing to report': a semilongitudinal investigation of the print media coverage of sportswomen in British Sunday newspapers, Media, Culture \& Society 36.5: 595-609

5 French S (2013) Still not there: The continued invisibility of female athletes and sports in the New Zealand print media, pp. 39-50, Media International Australia

6 Godoy-Pressland, A (2016) No hint of bulging muscles: The surveillance of sportswomen's bodies in British print media, 17(6) pp. 744-759, Journalism

7 Womens Media Center (2015) The Status of Women in the U.S. Media 2015, Women's Media Centre, accessed at: www.womensmediacenter.com/reports/2015-statistics

8 Hannis and Strong (2007) The visibility of female journalists in Australian and New Zealand newspapers: The good news and the bad news, Australian Journalism Review 29.1:115.
9 Price J, Payne A (2019) 2019 Women for Media Report: 'You can't be what you can't see', Women's Leadership Institute Australia, accessed at: www.wlia.org.au/2019-women-for-media-report

${ }^{10}$ Schmidt, HC (2016) Women's sports coverage remains largely marginalized, Newspaper Research Journal, 37(3) p275-298, accessed at: journals.sagepub.com/doi/ abs/10.1177/0739532916663211\#

${ }^{11}$ Eime, R. (2019) Sport Participation Rates - Aggregation of 12 sports, Victoria 2017, VicHealth, Melbourne www.vichealth.vic.gov.au/media-and-resources/ publications/victorian-participation-in-organised-sport

${ }^{12}$ Boston Consulting Group (2017) Intergenerational Review of Australian Sport, Australian Sports Commission, Canberra, accessed 12 February, 2020 at: www.clearinghouseforsport. gov.au/research/smi/value_of_sport

${ }^{13}$ World Health Organization (2020) Health topics/health determinants/gender/gender definitions, accessed 3 March 2020 at: www.euro.who.int/en/health-topics/healthdeterminants/gender/gender-definitions

${ }^{14}$ Gender equality, health and wellbeing strategy 2017-19 (2017) VicHealth, accessed at: www.vichealth.vic.gov.au/ media-and-resources/publications/gender-equality-healthand-wellbeing 


\section{VicHealth}

Victorian Health Promotion Foundation PO Box 154 Carlton South

Victoria 3053 Australia

$T+61396671333 F+61396671375$

vichealth@vichealth.vic.gov.au

vichealth.vic.gov.au

twitter.com/vichealth

facebook.com/vichealth

VicHealth is committed to health equity, which means levelling the playing field between people who can easily access good health and people who face barriers, to achieve the highest level of health for everyone.

VicHealth acknowledges the support of the Victorian Government.

(C) VicHealth

May 2020

https://doi.org/10.37309/2020.10863

\section{YICTORIA \\ State
Government}

VicHealth acknowledges the Traditional Custodians of the land. We pay our respects to all Elders past, present and future. 